\title{
The World Has Changed
}

\author{
João Ferreira de Mello Júnior ${ }^{1}$ (1) \\ 1 Department of Otorhinolaryngology, Universidade de São Paulo, \\ São Paulo, SP, Brazil \\ Int Arch Otorhinolaryngol 2020;24(3):e393.
}

Dear Editor,

The current COVID-19 pandemic has shown us how technology can provide solutions to adapt to social isolation, minimizing the effects of physical distancing with the use of many videoconferencing platforms to keep us debating, dialoguing, teaching, learning and socializing.

Digital Information and Communication Technologies are considered attractive, didactic possibilities in medical teaching. ${ }^{1}$ Videos, including those presented via live streaming, have proven to be very useful in medicine. ${ }^{2}$

A recent systematic review of their role as a surgical teaching instrument stated that they are an efficient method that should be incorporated into usual teaching techniques. ${ }^{3}$

Considering this, why not use technology to increase the information-sharing potential that the International Archives of Otorhinolaryngology provides to the scientific community?

We have been working toward this goal for a few months. In this edition, we will start a section called "video data innovation." It will feature review articles written by experts in their fields, including short videos illustrating and enriching the written content.
Address for correspondence João Ferreira de Mello Júnior, MD, PhD, Department of Otorhinolaryngology, Universidade de São Paulo, Av. Dr. Enéas de Carvalho Aguiar 255, $6^{\circ}$ andar, sala 6167, São Paulo, SP, 05403-000, Brazil (e-mail: jmellojr@gmail.com).

To watch the videos, simply direct your cell phone camera to the $\mathrm{QR}$ code in the article and the video will start playing automatically.

It was an honor to be invited by Professor Geraldo Pereira Jotz to coordinate this section.

Hoping to contribute to the growth of our journal, I wish you all have a great read.

\section{References}

1 Gorgens PRC, Andrade PCR. Medical education and digital information and communication technologies: possibilities and dilemmas. Rev Med Minas Gerais 2018;28:e-2004Doi: 10.5935/2238-3182.20180154

2 Wiecha JM, Gramling R, Joachim P, Vanderschmidt H. Collaborative elearning using streaming video and asynchronous discussion boards to teach the cognitive foundation of medical interviewing: a case study. J Med Internet Res 2003;5(02):e13Doi: 10.2196/jmir.5.2.e13

3 Ahmet A, Gamze K, Rustem M, Sezen KA. Is Video-Based Education an Effective Method in Surgical Education? A Systematic Review. J Surg Educ 2018;75(05):1150-1158Doi: 10.1016/j. jsurg.2018.01.014
DOI https://doi.org/ 10.1055/s-0040-1714144. ISSN $1809-9777$. 